\title{
Building the Case for an "Architectonic" Function of Rhetoric in Health Services Research
}

\section{J ohn J oseph Rief}

University of Pittsburgh

Pittsburgh, PA

Poroi 10,1 (J anuary 2014)

Keywords: translational research, health services research, interdisciplinarity, rhetoric as architectonic, Richard McKeon

\section{"Architectonic" Rhetoric in Health Services Research}

Participation on this panel provided an excellent opportunity to step back and reflect on my research program and its relationship to my professional formation. For this reason, I want to thankJ ean Goodwin for her significant work in bringing all of us together, Leah Ceccarelli and J amie Vernon for their insightful responses, the other participants for their excellent contributions, and the attendees for the lively discussion that followed our presentations.

For the last year and a half, I have been a postdoctoral scholar in an interdisciplinary research fellowship program at the Institute for Clinical Research Education in the University of Pittsburgh's School of Medicine. The program provides training, research support, and time to develop the skills needed to be an independent health services researcher. One definition of health services research composed by the Academy for Health Services Research and Health Policy states that,

Health services research is the multidisciplinary field of scientific investigation that studies how social factors, financing systems, organizational structures and 
processes, health technologies, and personal behaviors affect access to healthcare, the quality and cost of healthcare, and ultimately our health and well-being. Its research domains are individuals, families, organizations, institutions, communities, and populations. (Lohr \& Steinwachs, 2002, 16)

Those of us who, like myself, are trained in a humanistic rhetoric program will likely wonder about the role of rhetoric in "scientific investigation." A mountain of scholarship has demonstrated the porous boundaries between science and the humanities. Thus, the debate about the value of interdisciplinary research (if done well) need not take up space in the following pages. However, the question about whether my work meets the demands of the "multidisciplinary field" of scientific investigators I have joined is important to the ongoing course of my career. Thus, the following pages provide one answer to the question: what role(s) should rhetoric play in health services research?

If the history of the rhetoric of science and inquiry movement is to be my guide, one answer is that rhetoric is a powerful method of analysis, one that can uncover the linguistic, suasive, and constitutive elements of scientific discovery and dissemination (Harris, 1997). ${ }^{1}$ Another possibility that emerges from this tradition, one noted in J ean Goodwin's introduction to this set of papers, is to imagine the role of rhetoricians as primarily oriented toward the improvement of communication in other research domains, a view that highlights the therapeutic function of rhetoric as a means of solving problems and enhancing social relationships (Harris 1997). ${ }^{2}$

On my view, discovering whether these trajectories provide openings for rhetoric in health services research requires attention to the "rhetorical situation" in which collaboration emerges as a response to specific problems (Bitzer, 1992/ 1968). To wit, many of my most fruitful collaborations with scientists have come from requests for help in promoting better writing and speaking skills in a variety of contexts. In these cases, an invitation emerges for

\footnotetext{
${ }^{1}$ For more recent discussions relevant to rhetoric and medicine, see e.g., Leach (2009) and Mitchell \& McTigue (2012). In a related vein, there is a growing scholarly investment in the study of public controversies that erupt in reaction to the dissemination of clinical research findings. See e.g., Keränen (2010) and Lynch (2011).

${ }^{2}$ For an extensive literature review on the role of rhetoric as therapeutic, see my dissertation project, Rief (2012, pp. 20-26). Excellent work on this topic can also be found in Peters (1999).
} 
collaboration from a rhetorical situation in which a particular problem has been diagnosed as a disorder of communication.

As far as I am concerned, both trajectories are crucial to the project of integrating rhetoric into health services research because they respond to manifest needs. For example, as qualitative research of practitioner and patient feedback blossoms throughout the health sciences, attention to language use (in particular, its meaning and the practical consequences it has for provider practice and patient care) has taken on vital importance to the scientific project of improving health outcomes (Segal, 2005). What's more, as provider-patient communication and collaboration continues to take center stage in efforts to promote "patient-centeredness" in healthcare research, delivery, and policy (Millenson \&Macri, 2012), the use of rhetoric not just as method of analysis but also as tool for improving patient care should not seem foreign to health services researchers. And, in fact, it has not, at least in terms of my experiences at the University of Pittsburgh where I have been welcomed into funded collaborations with a variety of researchers excited to learn about the art of rhetoric and how it might contribute unexplored methods and novel insights to their ongoing research projects. However, these two trajectories may not fully address the ways in which rhetoric could enliven health services research by responding to extant gaps, fissures, or crises in practice, method, and methodology. In her introduction, Goodwin notes the emergence of "translational research" at the National Institutes of Health as a critical development for rhetoricians, even an invitation for their involvement in the research process. ${ }^{3}$ I tend to agree.

In 2003, then director of the National Institutes of Health (NIH), Elias A. Zerhouni, announced a new "Roadmap" meant to directly synergize the work of clinical researchers and practitioners. Most importantly, this "Roadmap" was designed to deal with the increasingly complex world of medical care in which the expertise needed to treat patients is not concentrated in one person but dispersed in networks of researchers and providers that must find ways to work collaboratively (Zerhouni, 2003; Kaiser \& Couzin, 2003). One can see this complexity at work in the definition of health services research proffered earlier. What's more, according to Zerhouni, enhancing the prospects for improved health in this complex environment requires "the methodologic research necessary to develop or improve research tools" that fuel "clinical and translational research" turning them into "powerful engines of

\footnotetext{
${ }^{3}$ For more on the role of rhetoric and communication in translational research, see Roundtree, Dorsten, \& Rief (2011).
} 
creativity" (Zerhouni, 2005, 1622). Furthermore, according to Stephen H. Woolf, in the domain of health services, "translational research" has taken on extreme importance for those invested in: "translating research into practice; ie, ensuring that new treatments and research knowledge actually reach the patients or populations for whom they are intended and are implemented correctly" (2008, Woolf, 211). ${ }^{4}$ When taken in tandem, Zerhouni's call and Woolf's definitional work point to the need for articulating just what translational research should achieve. In short, they (and many others) are calling for methodological ingenuity, for new approaches that can connect disparate elements of the larger healthcare system (e.g., researchers, clinical practitioners, and patients). ${ }^{5}$

Answering such an invitation, and subjecting one's intellectual and methodological approaches to intense scrutiny within a larger interdisciplinary medium, is daunting. It means advancing rhetoric within a "demand-driven" framework in which its tools are deployed in the effort to address extant problems (Mitchell, 2010). ${ }^{6}$ On one reading, Zerhouni's invitation might be seen as an opportunity already gone sour due to the fact that the pre-figured problems of medical research will dominate judgments about the relevance of new research methods brought to bear. Alternatively, one can view Zerhouni's call as an opportunity to build collaborative possibilities that make rhetoric relevant without obviating its role in agenda setting. This is in keeping with Bitzer's view of rhetoric as situated - as emerging from the possibilities and "constraints" of any given situation (Bitzer, 1992/ 1968).

While I have utilized both rhetoric as method and as pedagogical tool in answering Zerhouni's call in my own professional development, I have also cultivated a separate vision for the integration of rhetoric as a translational research tool in the domain of health services research. In short, I have developed a sense of rhetoric as not only a "methodologic tool" but also a methodology, an orientation to the coordination of theory and practice in the generation of a variety of approaches that can respond to particular problems of communication and suasion in health-related research.

To cultivate this perspective, I have turned to the work of Richard McKeon, whose sense of rhetoric focuses on its

\footnotetext{
${ }^{4}$ For more on the definition of translational research, see Feldman (2008) and Mitchell \& McTigue (2012)

${ }^{5}$ This paragraph contains adapted text from Rief (2012, pp. 322-323 and 327).

${ }^{6}$ A topic I more fully address in Rief (2012, pp. 26-32).
} 
"architectonic" function (McKeon, 1971). ${ }^{7}$ Because it responds to the " 'fragmentation' of knowledge, community, and communication," (McKeon, 1971, 51), McKeon's sense of rhetoric as an organizing art is fitted to the invitational circumstances in the domain of health services and translational research. By suggesting that, "What rhetoric should be and to what conditions it is adapted are not separate theoretic questions but the single practical question of producing schemata to guide the use of the productive arts in transforming circumstances" (McKeon, 1971, 45), McKeon opens the door for emphasizing arrangement as the central function of rhetoric, an emphasis that fits the situation described in Zerhouni's call to integrate the activities of multiple researchers and practitioners with different approaches.

Accordingly, as Mark Backman notes in his introduction to McKeon's Rhetoric: Essays in Invention \& Discovery, “McKeon's conception of rhetoric as an architectonic productive art provides an intellectual principle to organize considerations of change and its attendant dissonance in the modern world" (Backman 1987, xxiii). Thus, McKeon's view of rhetoric is relevant to the larger project of integrating knowledge about and practical solutions for problems within the "social factors", "organizational structures and processes", "health technologies," and "personal behaviors" that enervate effective healthcare (Lohr \& Steinwachs, 2002, 16). Projects to engage in such integration are already underway, most notably Edward H. Wagner's attempt to synergize the various components of chronic care into an overall architecture of care (Wagner et al., 2001). In a way that does justice to the vast organizational prowess of McKeon, Wagner has promoted the idea of integrating research about provider-patient communication, institutional and community-wide quality improvement, and technological advancement into strategies for system-wide transformation. However, attention to how communication practices affect such integration has not been a focus of such efforts, leaving the door open for rhetoricians to take up the task.

While McKeon's architectonic project seems apposite to the problems of complexity, integration, and arrangement in contemporary healthcare, promoting this third vision of what rhetoric might do in health services research is risky. Whenever someone claims the status of "master art," there exists the potential consequence of offending those with alternative institutional and

\footnotetext{
${ }^{7}$ For an insightful take on the role of McKeon's "architectonic” view of rhetoric in the history of the rhetoric of science and inquiry movement and its implications for interdisciplinarity, see Depew (2010), and Goodnight, this issue.
} 
scholarly commitments. Thus crafting an argument for the usefulness of this approach cannot and should not happen in a vacuum. The power of rhetoric to connect disparate elements of the healthcare system will need to be demonstrated. This is my current challenge as I seek to unravel the complex interplay between provider-patient communication, the use of technology to deliver health services to patients outside the clinical setting, and the dissemination of new findings to practitioners and patients in persuasive ways. ${ }^{8}$

In particular, my research poses the question: How does McKeon's vision of rhetoric promote the development of innovative research questions in translational and health services research? It does so by changing the scope of these questions. Instead of asking, for example, whether " $\mathrm{X}$ " technology effectively promotes a certain health outcome, or the effectiveness of one style of counseling in weight-loss interventions, a McKeon-inflected research question would wonder about how asking such questions fits into the larger project of designing effective healthcare systems. Doing so would require at least some attention to the circulation of discourses both in and between various practitioners and patients as well as the variety of disciplines that are necessary to effective care delivery.

The role of the rhetorical researcher in health services, in my view, is the coordination of the various discourses, approaches, and findings of other team members on a project into an artful arrangement, one that would implicate changes at every level of healthcare from provider-patient dialogue to practitioner training, institutional design, the deployment of a variety of health technologies to address the limits of the clinical environment, and the persuasive dissemination of research findings from one context into another (Rief, 2012). Ideally, the rhetorician member of a research team would draw on all three models of rhetorical work identified in this paper, thus deploying rhetoric as practice, method, and methodology. Doing this would show how rhetoric can contribute to the cultivation of best practices in health services research, practices rooted in the translation and dissemination of findings about an overall process as opposed to piecemeal efforts to understand one element of a system. Succeeding in this effort would not only provide ample evidence of rhetoric's role in translational research in the domain of health services, it would also respond to the specific needs and quandaries facing researchers in

\footnotetext{
${ }^{8}$ Others have discussed the role of rhetoric in the dissemination of medical research in detail. See e.g., Mitchell \& McTigue (2012) and Leach (2009).
} 
these areas: the coordination of methods and disciplinary

discourses to affect transformative change.

Copyright (C) 2014 J ohn J oseph Rief

\section{ACKNOWLEDGMENTS}

The author is currently supported by a fellowship funded by the Agency for Healthcare Research and Quality and awarded through the Institute for Clinical Research Education and the RANDUniversity of Pittsburgh Scholars Program at the University of Pittsburgh (Grant \# 5T32HS17587-5).

\section{REFERENCES}

Backman, Mark. (1987). Introduction: Richard McKeon and the renaissance of rhetoric. In Richard McKeon's Rhetoric: Essays in Invention \& Discovery, edited by Mark Backman, pp. vii-xxxii. Woodbridge, CT: OxBow Press

Bitzer, Lloyd F. (1992/ 1968). The Rhetorical Situation. Philosophy and Rhetoric, 25, supplement, 1-14.

Depew, David. (2010). Revisiting Richard McKeon's Architectonic Rhetoric: A Response to Richard McKeon's 'The Uses of Rhetoric in a Technological Age: Architectonic Productive Arts". In MarkJ. Porrovecchio's (Ed.) Reengaging the Prospects of Rhetoric: Current Conversations and Contemporary Challenges, pp. 37-56 (New York, NY: Routledge).

Feldman, Arthur M. (2008). Does academic culture support translational research? Clinical and Translational Science, 1(2), 87-88.

Harris, Randy A. (1997). Introduction. In Randy A. Harris (Ed.) Landmark Essays on Rhetoric of Science: Case Studies, pp. xi-xlv. Mahwah, N.J .: Hermagoras Press.

Kaiser, J ocelyn \& Couzin, J ennifer. (2003). Speeding up delivery: NIH aims to push for clinical results. Science, 302(5642), 2829. 
Keränen, Lisa. (2010). Scientific Characters: Rhetoric, Politics, and Trust in Breast Cancer Research. Tuscaloosa, AL: University of Alabama Press.

Leach, J oan. (2009). The art of medicine: Valuing communication. The Lancet, 373, 2104-2105.

Lohr, Kathleen N. \& Steinwachs, Donald M. (2002). Health services research: An evolving definition of the field. Health Services Research, 37(1), 15-17.

Lynch, J ohn A. (2011). What are stem cells? Definitions at the intersection ofscience and politics. Tuscaloosa, AL: University of Alabama Press.

McKeon, Richard. (1971). The uses of rhetoric in a technological age: Architectonic productive arts. In Lloyd F. Bitzer \& Edwin Black's (Eds.) The Prospect of Rhetoric: Report of the National Developmental Project, pp. 44-63 (Englewood Cliffs, N.J .: Prentice-Hall, Inc.).

Millenson, Michael L. \& Macri, J uliana. (2012). Will the Affordable Care Act Move Patient-Centeredness to Center Stage? Timely Analysis of Immediate Health Policy Issues (Urban Institute). Retrieved from http://www.rwjf.org/qualityequality/product.jsp?id=74054\&cid=X EM_A 765.

Mitchell, Gordon R. (2010). Switch-Side Debating Meets DemandDriven Rhetoric of Science. Rhetoric \& Public Affairs, 13(1), 95- 120.

Mitchell, Gordon R. \& McTigue, Kathleen M. (2012). Translation Through Argumentation in Medical Research and Physician Citizenship. J ournal of Medical Humanities, 33, 83-107.

Peters, J ohn D. (1999). Speaking into the air: A history of the idea of communication. Chicago, IL: University of Chicago Press.

Rief, J ohn J . (2012). Searching for the Good Life: Rhetoric, Medicine, and the Shaping of Lifestyle. $\mathrm{PhD}$ dissertation. Pittsburgh, PA: University of Pittsburgh.

Roundtree, Aimee K., Dorsten, Aimee, \&Rief, J ohn J . (2011). Improving patient activation in crisis and chronic care through rhetorical approaches to new media technologies. POROI, 7(1). Retrieved from http://ir.uiowa.edu/cgi/viewcontent.cgi?article=1081\&context=por oi. 
Segal, J udy Z. (2005). Health and the rhetoric of medicine Carbondale, IL: Southern Illinois University Press.

Wagner, Edward H., Austin, Brian T., Davis, Connie, Hindmarsh, Mike, Schaefer, J udith \& Bonomi, Amy. (2001). Improving chronic illness care: Translating evidence into action. Health Affairs (Millwood), 20(6), 64-78.

Woolf, Stephen H. (2008). The meaning of translational research and why it matters. Journal of the American Medical Association, 299(2), 211-213.

Zerhouni, Elias A. (2003). The NIH Roadmap. Science, 302(5642), 63-72.

Zerhouni, Elias A. (2005). Translational and clinical science - Time for a new vision. The New England J ournal of Medicine, 353(15), 1621-1623. 